\title{
Excellent Response to Gefitinib in a Patient with Erlotinib Refractory, Exon 21, L858r Epidermal Growth Factor Receptor-Mutated Lung Adenocarcinoma
}

Sir,

A 61-year-old man, a nonsmoker, presented to our hospital with a right lung mass and right-sided, rapidly refilling, massive pleural effusion with multiple, bilateral lung, liver, and bone metastases.
Bronchoscopic biopsy revealed adenocarcinoma of the lung. He was started on pemetrexed and carboplatin every 3 weeks. The epidermal growth factor receptor (EGFR) mutation analysis done by polymerase chain reaction technique revealed an exon 
21, L858R (an arginine for leucine substitution at amino acid 858) mutation.

He had an excellent clinical response to the first cycle of chemotherapy and was thus given six cycles followed by 4 weekly maintenance with single-agent pemetrexed. After the third cycle of maintenance, he developed progressive disease which was confirmed by an 18-fluorodeoxyglucose positron emission tomography (PET) scan. He was started on erlotinib $150 \mathrm{mg} /$ day to which there was no response. The PET scan done at 8 weeks was suggestive of progressive disease [Figure 1a] with a heterogeneously enhancing mass lesion $7.9 \mathrm{~cm} \times 5.5 \mathrm{~cm} \times 7.5 \mathrm{~cm}$ (previously $5.9 \mathrm{~cm} \times 4.6 \mathrm{~cm} \times 7 \mathrm{~cm}$ ) in the right suprahilar region, pulmonary parenchymal, mediastinal lymph nodal, and solitary skeletal metastases and right pleural effusion. The patient was not receiving any medications that might change the serum levels of the EGFR inhibitors, such as CYP3A4 inducers or inhibitors.

He was started on gefitinib $250 \mathrm{mg}$ a day. Within 2 weeks, he reported significant clinical improvement. A PET scan done 3 months later revealed partial response with marked resolution of the lung lesions [Figure 1b]. The patient exhibited excellent radiological and clinical response to the drug. The response lasted for 14 months when unfortunately the disease progressed. He died 3 months later after disease progression (no additional mutation or T790 mutation detected on repeat biopsy) after failing to respond to afatinib and nivolumab as salvage therapies.

\section{Discussion}

Gefitinib and erlotinib are small-molecule reversible competitive tyrosine kinase inhibitors (TKIs) of ATP binding at the active site of the EGFR kinase. Among patients with EGFR-mutant tumors, response rates of up to $83 \%$ have been described, ${ }^{[1]}$ yet approximately $20 \%-30 \%$ cases remain refractory to initial TKI treatment.

The role of gefitinib in patients refractory to erlotinib has not been evaluated. There are significant differences between EGFR-TK-activating mutations with regard to clinical response to small-molecule inhibitors. The L858R substitution, also seen in our patient, shows good responses to gefitinib. ${ }^{[2-4]}$

This is only the second case reported in the literature, wherein a patient with erlotinib failure has responded to gefitinib. The sole case report in which a patient with metastatic NSCLC with leptomeningeal disease responded to gefitinib after erlotinib failure also harbored the L858R mutation. Additional analyses also revealed the presence of the $E G F R^{\mathrm{E} 884 \mathrm{~K}}$ mutation. It has been found that the presence of certain other mutations such as $E G F R^{\mathrm{E} 884 \mathrm{~K}}$ can facilitate increased resistance to erlotinib while conferring increased gefitinib sensitivity: coexistence with the L858R mutation magnifies these effects. ${ }^{[5]}$

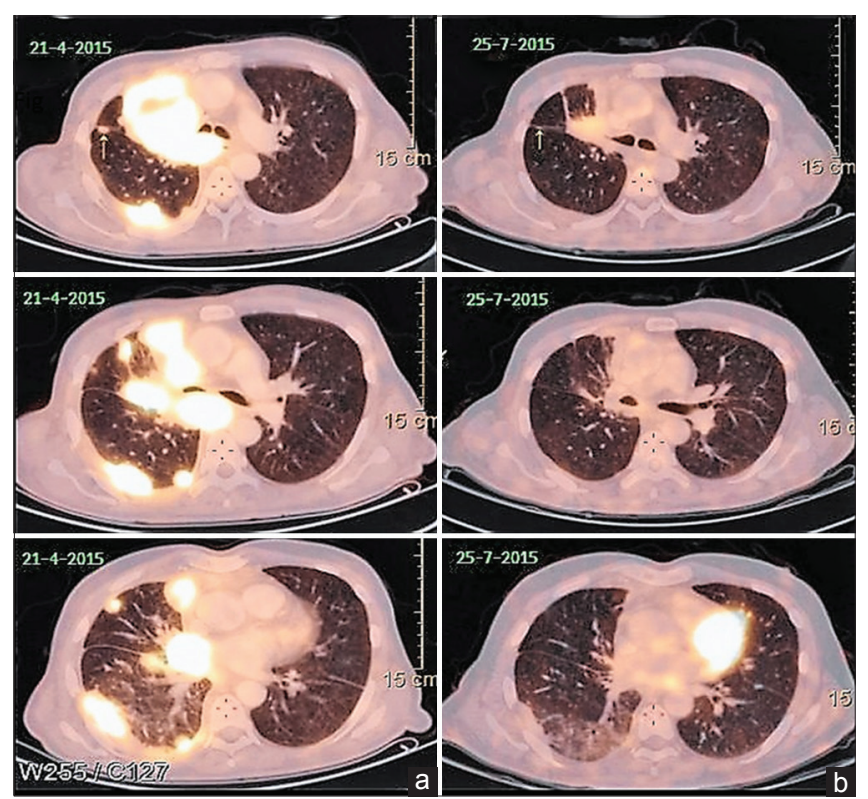

Figure 1: (a) Left-sided images showing positron emission tomography scan revealing right suprahilar mass lesion with pulmonary parenchymal involvement after erlotinib therapy and before the start of gefitinib. (b) Right-sided images showing positron emission tomography scan done 3 months after institution of gefitinib showing partial response

\section{Conclusions}

Use of gefitinib in patients refractory to erlotinib needs to be further explored, considering the excellent results in our case.

\section{Declaration of patient consent}

The authors certify that they have obtained all appropriate patient consent forms. In the form the patient(s) has/have given his/her/their consent for his/her/their images and other clinical information to be reported in the journal. The patients understand that their names and initials will not be published and due efforts will be made to conceal their identity, but anonymity cannot be guaranteed.

Financial support and sponsorship

Nil.

\section{Conflicts of interest}

There are no conflicts of interest.

Ajay Gupta

Department of Medical Oncology, Vancouver General Hospital, All India Institute of Medical Sciences, New Delhi, India

Address for correspondence: Dr. Ajay Gupta, P-41, South Extension Part 2, New Delhi - 110 049, India. E-mail: ajayajaygupta2002@rediffmail.com

\section{References}

1. Zhou $\mathrm{C}, \mathrm{Wu}$ YL, Chen G, Feng J, Liu XQ, Wang C, et al. Erlotinib versus chemotherapy as first-line treatment for patients with advanced EGFR mutation-positive non-small-cell lung 
cancer (OPTIMAL, CTONG-0802): A multicentre, open-label, randomised, phase 3 study. Lancet Oncol 2011;12:735-42.

2. Pao W, Miller V, Zakowski M, Doherty J, Politi K, Sarkaria I, et al. EGF receptor gene mutations are common in lung cancers from "never smokers" and are associated with sensitivity of tumors to gefitinib and erlotinib. Proc Natl Acad Sci U S A 2004;101:13306-11.

3. Chen YR, Fu YN, Lin CH, Yang ST, Hu SF, Chen YT, et al. Distinctive activation patterns in constitutively active and gefitinib-sensitive EGFR mutants. Oncogene 2006;25:1205-15.

4. Yun CH, Boggon TJ, Li Y, Woo MS, Greulich H, Meyerson M, et al. Structures of lung cancer-derived EGFR mutants and inhibitor complexes: Mechanism of activation and insights into differential inhibitor sensitivity. Cancer Cell 2007;11:217-27.

5. Choong NW, Dietrich S, Seiwert TY, Tretiakova MS, Nallasura V, Davies GC, et al. Gefitinib response of erlotinib-refractory lung cancer involving meninges - Role of EGFR mutation. Nat Clin Pract Oncol 2006;3:50-7.
This is an open access journal, and articles are distributed under the terms of the Creative Commons Attribution-NonCommercial-ShareAlike 4.0 License, which allows others to remix, tweak, and build upon the work non-commercially, as long as appropriate credit is given and the new creations are licensed under the identical terms.

\section{Access this article online}

\begin{tabular}{|l|l|}
\multicolumn{2}{|c|}{ Access this article online } \\
\hline Quick Response Code: & Website: \\
& www.ijmpo.org \\
\cline { 2 - 2 } & DOI: \\
\hline
\end{tabular}

How to cite this article: Gupta A. Excellent response to gefitinib in a patient with erlotinib refractory, exon 21, L858r epidermal growth factor receptor-mutated lung adenocarcinoma. Indian J Med Paediatr Oncol 2018;39:421-3.

C 2018 Indian Journal of Medical and Paediatric Oncology | Published by Wolters Kluwer - Medknow 